\title{
Size-Dependent Interactions of Lipid-Coated Gold Nanoparticles: Developing a Better Mechanistic Understanding Through Model Cell Membranes and in vivo Toxicity
}

This article was published in the following Dove Press journal:

International Journal of Nanomedicine

\author{
Arek M Engstrom (iD) \\ Ryan A Faase $\mathbb{D}^{2}$ \\ Grant W Marquart $\mathbb{D}^{3}$ \\ Joe E Baio ${ }^{2}$ \\ Marilyn R Mackiewicz (1D) ${ }^{3}$ \\ Stacey L Harper $\mathbb{D}^{1,2,4}$ \\ 'Department of Environmental and \\ Molecular Toxicology, Oregon State \\ University, Corvallis, OR, United States; \\ ${ }^{2}$ School of Chemical, Biological, and \\ Environmental Engineering, Oregon State \\ University, Corvallis, OR, United States; \\ ${ }^{3}$ Department of Chemistry, Portland \\ State University, Portland, OR, United \\ States; ${ }^{4}$ Oregon Nanoscience and \\ Microtechnologies Institute, Corvallis, \\ OR, United States
}

Introduction: Humans are intentionally exposed to gold nanoparticles (AuNPs) where they are used in variety of biomedical applications as imaging and drug delivery agents as well as diagnostic and therapeutic agents currently in clinic and in a variety of upcoming clinical trials. Consequently, it is critical that we gain a better understanding of how physiochemical properties such as size, shape, and surface chemistry drive cellular uptake and AuNP toxicity in vivo. Understanding and being able to manipulate these physiochemical properties will allow for the production of safer and more efficacious use of AuNPs in biomedical applications.

Methods and Materials: Here, AuNPs of three sizes, $5 \mathrm{~nm}, 10 \mathrm{~nm}$, and $20 \mathrm{~nm}$, were coated with a lipid bilayer composed of sodium oleate, hydrogenated phosphatidylcholine, and hexanethiol. To understand how the physical features of AuNPs influence uptake through cellular membranes, sum frequency generation (SFG) was utilized to assess the interactions of the AuNPs with a biomimetic lipid monolayer composed of a deuterated phospholipid 1.2-dipalmitoyl-d62-sn-glycero-3-phosphocholine (dDPPC).

Results and Discussion: SFG measurements showed that $5 \mathrm{~nm}$ and $10 \mathrm{~nm}$ AuNPs are able to phase into the lipid monolayer with very little energetic cost, whereas, the $20 \mathrm{~nm}$ AuNPs warped the membrane conforming it to the curvature of hybrid lipid-coated AuNPs. Toxicity of the AuNPs were assessed in vivo to determine how AuNP curvature and uptake influence cell health. In contrast, in vivo toxicity tested in embryonic zebrafish showed rapid toxicity of the $5 \mathrm{~nm}$ AuNPs, with significant 24 hpf mortality occurring at concentrations $\geq 20 \mathrm{mg} / \mathrm{L}$, whereas the 10 $\mathrm{nm}$ and $20 \mathrm{~nm}$ AuNPs showed no significant mortality throughout the five-day experiment.

Conclusion: By combining information from membrane models using SFG spectroscopy with in vivo toxicity studies, a better mechanistic understanding of how nanoparticles (NPs) interact with membranes is developed to understand how the physiochemical features of AuNPs drive nanoparticle-membrane interactions, cellular uptake, and toxicity.

Keywords: gold nanoparticle, vibrational spectroscopy, nanoparticle-biological interactions, hybrid lipid-coated nanoparticle, toxicity, size-dependent interaction, zebrafish

\section{Introduction}

Nanoparticles (NPs) have many novel applications in medicine, one of which is the development of nanoparticle-based therapeutics and imaging agents. ${ }^{1}$ Incorporating drugs into NP platforms that serve as drug delivery vehicles provides a variety of benefits: improved solubility and clinical efficacy as well as decreased degradation, physiologic clearance rates, systemic toxicity. ${ }^{2}$ However, these benefits do not come
Correspondence: Stacey L Harper

Email Stacey.Harper@oregonstate.edu 
without their costs. The approval of the first FDAapproved nanotherapeutic Doxil ${ }^{\circledR}$ in 1995 was followed by more than 50 other nanotherapeutics for use in clinical trials. ${ }^{3}$ Most nanoparticle-based delivery systems are based on liposomal or polymer formulations; however, metalbased colloidal systems such as gold nanoparticles (AuNPs) are also being investigated for use in cancer therapy. ${ }^{4}$ For example, AuNPs have also been heavily researched for use in plasmonic photothermal therapy (PPTT), ${ }^{4-9}$ tumor-targeted drug delivery, ${ }^{4,10-12}$ and utilized to fight multi-drug resistant cancers. ${ }^{13-16}$ Consequently, their growing use in clinical trials, cancer therapies, and other biomedical applications have brought to light a need to better understanding of interactions between nanomaterials and biological systems. ${ }^{17}$ That is, there is a critical need to better understand how the physiochemical properties of NPs, such as size, shape, surface area, charge, and surface chemistry drive cellular uptake and toxicity. An improved understanding of nanoparticlebiological interactions (NBIs) and toxicity are critical if we are design of safer and more efficacious AuNP-based platforms that can be used for imaging and drug delivery.

Although the core of AuNPs is considered to be nontoxic and biologically inert, ${ }^{18}$ many studies show that changes to the size, shape, surface charge and coating of AuNPs can elicit different toxic responses. For example, changing the surface charge on AuNPs results in differential sub-organ distribution, ${ }^{19}$ pharmacokinetics, excretion, and tumor uptake in mice. ${ }^{20}$ The coating on the surface of AuNPs provides many benefits such as allowing for the delivery of small molecules to specific sites in the body and plays a major role in the biocompatibility of AuNPs for use in biomedical applications. For example, natural ligands such as glutathione and modified peptidederivatives, when coated onto AuNPs, were found to be biocompatible in zebrafish compared to those that had impurities. $^{21}$ More recently, poly-ethylene-glycol (PEG)coated AuNPs showed lower hepatotoxicity in rats when compared to uncoated AuNPs. ${ }^{22}$ In addition to surface charge and coating, the size and shape of the AuNPs also critically affect efficacy and toxicity. Studies have shown that smaller gold nanospheres have increased cellular uptake, compared to their larger AuNPs with the same surface coating. ${ }^{23-25}$ This size-dependent biodistribution and excretion of AuNPs has been observed in mice exposed to repeated doses of AuNPs and is often attributed to their differential mechanisms of cellular uptake. ${ }^{26}$ Mironava et al showed that $45 \mathrm{~nm}$ AuNPs penetrate cells via clathrin-mediated endocytosis, while the smaller $13 \mathrm{~nm}$ AuNPs entered cells via phagocytosis. ${ }^{27}$ While these studies assess the size-dependent nature of AuNP toxicity, they do so independently of the studies that assess sizedependent cellular uptake making it difficult to understand the connection between the two as various properties of AuNPs vary from study-to-study. In order to adequately assess and correlate the size-dependent nature of AuNP uptake and toxicity, a single study must be performed, assessing the interactions of the AuNPs at various levels of biological complexity ranging from cellular to organism.

While in vitro and in vivo studies of NP uptake have provided a wealth of knowledge regarding the mechanism and efficiency of NP uptake, distribution, and toxicity, consensus regarding dosimetry based on NP size is still lacking as these studies have not agreed on which is more important size, shape, or surface area. ${ }^{28-31}$ There is a critical need for a systematic study to correlate the effects of the physiochemical features of NPs with cell membrane response if we are to design better NPs with minimal human health impact for biomedical applications. One approach to a systematic study is through the use of well-studied biomimetic lipid monolayers that have been employed to assess the interactions of biomolecules or NPs with a lipid monolayer. ${ }^{32-41}$ Structural changes in the biomimetic lipid monolayer are monitored by sum-frequency generation (SFG) vibrational spectroscopy, a second-order nonlinear optical technique. SFG is capable of detecting the adsorption and orientation of biomolecules at sub-micromolar concentrations. ${ }^{42-46}$ Through the utilization of a fixed visible laser, pulsed in temporal and special synchronicity with a tunable-infrared laser, SFG can measure sum-frequency photons. Sumfrequency photons generated by nonlinear optical frequency mixing carry a vibrational spectrum sensitive to molecular order. SFG is capable of directly identifying interactions between NPs and model cell membranes with molecular resolution. ${ }^{33-41,47-55}$ Using SFG to directly probe the order of the acyl chains of the lipid monolayer allows for direct observation of how the AuNPs change the packing and ordering of the lipids of the model cell membrane to provide fundamental understanding of how NPs interact with cells to drive uptake and if this correlated with toxicity.

Here, our objective is to evaluate the in vivo effects of various sized AuNPs ( $5 \mathrm{~nm}, 10 \mathrm{~nm}$, and $20 \mathrm{~nm}$ core size) and establish relationships between in vivo toxicity and cellular uptake through interactions of AuNPs with a biomimetic model cell membrane. For these studies, AuNPs were coated 
with robust and tightly packed lipid bilayer composed of sodium oleate (SOA), hydrogenated phosphatidylcholine (hPC), and hexanethiol (HT). We hypothesized that the smaller, $5 \mathrm{~nm}$, AuNPs would cause increased toxicity as their smaller size will allow for more efficient integration into cellular membranes, and thus uptake into cells at a lower energetic cost than their larger $10 \mathrm{~nm}$ and $20 \mathrm{~nm}$ counterparts. The toxicity of the AuNPs were assessed in vivo. For the in vivo toxicity testing, embryonic zebrafish (Danio rerio) was used as a model organism because of their rapid development and ease of use in nanotoxicology studies. ${ }^{56-61}$ Embryonic zebrafish have very similar molecular signaling processes, cell structure, anatomy, and physiology as other higher-order vertebrates, including humans. ${ }^{62-65}$ Hence, embryonic zebrafish allow for observation of whole organism toxicity in a model that is relevant to human health, as humans are the ultimate target of many AuNP applications. Combining in vivo toxicity studies with complementation studies using SFG spectroscopy and model membranes we are able to elucidate our gap in knowledge in understanding of how NP size and curvature influence interactions with membranes to drive uptake and toxicity.

\section{Methods and Materials}

\section{Reagents}

Aqueous solutions of 5, 10, and $20 \mathrm{~nm}$ gold citrate-capped NPs were purchased from Ted Pella, characterization information has been provided in Table S1. Chloroform $\left(\mathrm{CHCl}_{3}\right)$ and L- $\alpha$-phosphatidylcholine-hydrogenated soy (HPC) were purchased from Sigma-Aldrich while 1.2-dipalmitoyl-d62-sn -glycero-3-phosphocholine (dDPPC) was from Avanti Polar Lipids Inc, Alabaster, AL, USA. Ninety-five percent 1-hexanethiol (HT) and sodium oleate were purchased from Sigma-Aldrich. Tween-20 was purchased from SigmaAldrich. Sodium phosphate monobasic monohydrate, sodium phosphate dibasic heptahydrate, sodium chloride, and hydrochloric acid were from BDH Chemicals. Sodium bicarbonate was from J.T. Baker. Nanopure water was from a Milli-Q ultra-pure system. Potassium cyanide $(\mathrm{KCN})$ was from Mallinckrodt. All reagents were used as received.

\section{Physical Measurements}

UV-Vis spectra were recorded in ultra-pure water using a USB4000 UV-visible-NIR spectrophotometer (Ocean Optics, Dunedin, FL, USA) with a $1.0 \mathrm{~cm}$ path length quartz cell.

\section{Preparation of Hybrid Lipid-Coated Spherical AuNP (Diameter $=5,10$, or 20 $\mathrm{Nm}$ )}

SOA $(9.1 \mu \mathrm{L}$ for $5 \mathrm{~nm}, 2.2 \mu \mathrm{L}$ for $10 \mathrm{~nm}$, and $0.514 \mu \mathrm{L}$ for $20 \mathrm{~nm}$ AuNPs of a $9.3 \mathrm{mM}$ solution in $\mathrm{H}_{2} \mathrm{O}$ ) was added to $1 \mathrm{~mL}$ of AuNPs (0.8 optical density (O.D.) for $5 \mathrm{~nm}$ (lambda max at $520 \mathrm{~nm}$ ), 0.8 O.D. for $10 \mathrm{~nm}$ (lambda max at $520 \mathrm{~nm}$ ), and 1.08 O.D. for $20 \mathrm{~nm}$ (lambda max at $524 \mathrm{~nm}$ ) in $\mathrm{H}_{2} \mathrm{O}$ ) and stirred for $20 \mathrm{~min}$. This was followed by the addition of preformed HPC liposomes $(87 \mu \mathrm{L}$ for 5 $\mathrm{nm}, 20 \mu \mathrm{L}$ for $10 \mathrm{~nm}$, and $8.7 \mu \mathrm{L}$ for $20 \mathrm{~nm}$ of a $0.54 \mathrm{mM}$ solution in sodium phosphate buffer $\mathrm{pH} 8$ ) and incubation for $40 \mathrm{~min}$. The HPC liposomes were prepared using a wellestablished method where a solution of HPC (50 $\mu \mathrm{L}$ of a $21.6 \mathrm{mM}$ solution in $\mathrm{CHCl}_{3}$ ) was evaporated under a stream of $\mathrm{N}_{2}$ as a thin film and placed under vacuum of $12 \mathrm{~h}$ to remove trace organic solvents prior to resuspension in $2 \mathrm{~mL}$ of $10 \mathrm{mM}$ phosphate buffer at $\mathrm{pH} 8.0$ for a final concentration of $0.54 \mathrm{mM}$ (Supplemental Materials). The solution was shaken vigorously to re-suspend the lipids and sonicated for 90 min until the cloudy solution was transparent. Finally, HT ( $4.2 \mu \mathrm{L}$ for $5 \mathrm{~nm}, 1 \mu \mathrm{L}$ for $10 \mathrm{~nm}$, and 0.65 $\mu \mathrm{L}$ for $20 \mathrm{~nm}$ of a $10 \mathrm{mM}$ solution in ethanol) was then added to the AuNP-SOA-HPC solution and stirred for an additional $30 \mathrm{~min}$. Before purification by ultracentrifugation, each $1 \mathrm{~mL}$ solution of Au-SOA-HPC-HT was stirred with Tween-20 $(47.2 \mu \mathrm{L}$ for $5 \mathrm{~nm}, 10.1 \mu \mathrm{L}$ for $10 \mathrm{~nm}$, and $4.3 \mu \mathrm{L}$ for $20 \mathrm{~nm}$ of a $10 \mathrm{mM}$ solution in $\mathrm{H}_{2} \mathrm{O}$ ) for $30 \mathrm{~min}$ to break up liposome-free NPs for removal. Purification of Au-SOA-HPC-HT was performed by ultracentrifugation with a Thermo Scientific Sorvall ST 40R at $4700 \mathrm{rpm}$ using GE Healthcare ultracentrifugal concentrators with a PES membrane (Vivaspin 20, MWCO $=10 \mathrm{kDa}$ ) in a 10 $\mathrm{mM}$ sodium phosphate buffer at $\mathrm{pH} 8.0$ (4 min $\mathrm{x} 10$ rounds).

\section{Stability and Cyanide Etch Studies}

For $\mathrm{NaCl}$ studies, $1 \mathrm{~mL}$ solutions of Au-SOA-HPC-HT (X=5, 10 , or $20 \mathrm{~nm}$ ) with an O.D. of 0.8 (or concentrations $4.7 \times 10^{13}$ $\mathrm{nps} / \mathrm{mL}=5 \mathrm{~nm}, 4.7 \times 10^{12} \mathrm{nps} / \mathrm{mL}=10 \mathrm{~nm}$, and $4.7 \times 10^{11} \mathrm{nps} /$ $\mathrm{mL}=20 \mathrm{~nm}$ ) were exposed to $5 \mathrm{M} \mathrm{NaCl}(\mathrm{aq})$ to yield final concentrations of $50 \mathrm{mM}, 150 \mathrm{mM}$, and $200 \mathrm{mM} \mathrm{NaCl}$. For the $\mathrm{pH}$ study, the $\mathrm{pH}$ was adjusted to 2 or 5 by the addition of 2 $\mathrm{M} \mathrm{HCl}$ (aq). For freshwater (FW) studies, a solution of FW at $\mathrm{pH} 7.4$ was prepared by adding 0.26 -g aquarium salt and 0.01 g sodium bicarbonate to $1 \mathrm{~L} \mathrm{DI}$ water. A $1 \mathrm{~mL}$ aliquot of the FW solution was combined with $1 \mathrm{~mL}$ of Au-SOA-HPC-HT $(5,10$, or $20 \mathrm{~nm}$ at O.D. 0.8) for a final O.D. of 0.4. To 
determine if the AuNPs were completely covered by a hybrid lipid membrane coating, Au-SOA-HPC-HT was exposed to 20 $\mu \mathrm{L}$ of $307 \mathrm{mM}$ of $\mathrm{KCN}$ for a final concentration of $6.14 \mathrm{mM}$ $\mathrm{KCN}$ for $1 \mathrm{hr}$. The UV-Vis spectra were taken for all samples described here where the percent change in the $\lambda_{\max }$ and $\mathrm{O}$. D. was monitored to assess NP stability.

\section{SFG Vibrational Spectroscopy and Lipid Monolayer Formation}

For the SFG setup, an EKSPLA Nd:YAG laser, operating at $50 \mathrm{~Hz}$, was used to generate both a fixed visible $\left(532 \mathrm{~nm}^{-1}\right)$ and tunable IR beam $\left(1000-4000 \mathrm{~cm}^{-1}\right)$. Beams were focused to approximately a $1 \mathrm{~mm}$ diameter spot at the interface. The visible and IR beams overlapped in space and time to produce SFG photons. Spectra were collected in $2 \mathrm{~cm}^{-1}$ steps with 200 acquisitions per step. Three consecutive spectra were collected and summed before and after the NPs interacted with the lipid monolayer. SFG spectra were collected in the $s s p$ polarization combination (s-polarized SFG, $s$-polarized visible, $p$-polarized IR) in the C-D vibrational region $\left(1900-2250 \mathrm{~cm}^{-1}\right)$ and the $\mathrm{C}-\mathrm{H}$ vibrational region (2800-3000 $\left.\mathrm{cm}^{-1}\right)$. The SFG spectra were normalized by dividing the collected signal at each wavelength by the visible and infrared beam intensities. The SFG spectra were fit with Equation 1. 35,66,67

$$
\chi^{(2)}(\omega)=\chi_{N R}^{(2)}+\sum_{\mathrm{q}} \frac{\mathrm{A}_{\mathrm{q}}}{\omega-\omega_{\mathrm{q}}+\mathrm{i} \Gamma_{\mathrm{q}}}
$$

Where $A_{q}, \Gamma_{q}$ and $\omega_{q}$ are the amplitude, full-width half max and frequency of the qth vibrational mode, respectively. $\chi^{(2)}$ and $\chi_{N R}^{(2)}$ are the second-order nonlinear susceptibility tensor and the nonresonant background, respectively.

A lipid monolayer comprised deuterated phospholipids was formed at the air/water interface in a polytetrafluoroethylene (PTFE) trough containing approximately $10 \mathrm{~mL}$ of MQ $\mathrm{H}_{2} \mathrm{O}$. The monolayer consisted of a deuterated 1.2-dipalmitoyl-d62-sn-glycero-3-phosphocholine (dDPPC) (Figure S1). The lipids were dissolved in $\mathrm{CHCl}_{3}$ at a concentration of $0.125 \mathrm{mg} / \mathrm{mL}$ and added dropwise to the surface of the $\mathrm{H}_{2}$ O layer using a Hamilton microsyringe in $5 \mu \mathrm{L}$ increments. The dDPPC contains isotopically labeled acyl chains to distinguish the vibrational modes from the lipid monolayer and NPs. After letting the $\mathrm{CHCl}_{3}$ evaporate, approximately 15 min, spectra were collected to ensure the desired packing of lipids at the air/water interface. Two packing densities of lipids were used for the experiment, according to Ingolfsson et al the average area per lipid on the outer leaflet of a cell membrane is between 51 and $55 \AA^{2}$ per molecule. ${ }^{68}$ This range is on the border of what is described by Roke et al as the liquid condensed (LC) and the mixed liquid condensed and liquidexpanded ( $\mathrm{LC}+\mathrm{LE})$ region. ${ }^{69}$ The $\mathrm{LC}$ region exists beneath areas of $47 \AA^{2}$ per molecule, while the $\mathrm{LC}+\mathrm{LE}$ region exists between areas of 50-80 $\AA^{2}$ per molecule. To achieve a lipid monolayer within the range of what is observed in a cellular membrane we chose to use two different packing densities to achieve the $\mathrm{LC}$ and $\mathrm{LC}+\mathrm{LE}$ environments for the AuNPs to interact. This was followed by the injection of Au-SOA-HPCHT beneath the air/water interface for a final concentration of $20 \mathrm{mg} / \mathrm{L}$. Following Au-SOA-HPC-HT injection, ${ }^{35}$ the NPs were allowed to equilibrate for $4 \mathrm{hrs}$ with the lipids to ensure homogeneity in the trough.

\section{Toxicity Studies}

In vivo Embryonic Zebrafish Toxicity

Adult zebrafish (Danio rerio) were maintained at Oregon State University's Sinnhuber Aquatic Research Laboratory (SARL) in a water flow-through system under standard laboratory conditions: constant temperature of $28^{\circ} \mathrm{C}$ under a 14:10 hour light-dark cycle. ${ }^{70}$ Embryos were collected and staged from group spawns of wild-type tropical 5D zebrafish. Staging is important to ensure that all embryos are at the same developmental stage at the start of each experiment. ${ }^{71}$ Embryos were enzymatically dechorionated at $6 \mathrm{hrs}$ post fertilization (hpf) using pronase (SigmaAldrich, St. Louis, MO, USA) following the procedure of Usenko et $\mathrm{al}^{72}$ Removal of the chorion is critical as the chorion has been shown to protect the embryo from exposure, serving as a physical barrier and sink for nanomaterials and other chemicals. ${ }^{73,74}$ At 8 hpf, the dechorionated embryos were individually exposed to $200 \mu \mathrm{L}$ of AuNP suspensions with concentrations of $2.5 \mathrm{mg} / \mathrm{L}, 5 \mathrm{mg} /$ $\mathrm{L}, 10 \mathrm{mg} / \mathrm{L}, 20 \mathrm{mg} / \mathrm{L}, 30 \mathrm{mg} / \mathrm{L}, 40 \mathrm{mg} / \mathrm{L}$, and $50 \mathrm{mg} / \mathrm{L}$ in fish water in clear flat-bottom 96 -well plates $(n=24$ per concentration). Plates were incubated at $26.9^{\circ} \mathrm{C}$ under a 14:10 hour light-dark cycle. At $24 \mathrm{hpf}$, embryos were evaluated for mortality, developmental progression, notochord malformations, and presence of spontaneous movement. Spontaneous movement a behavioral end point described by Kimmel et al as "rhythmic bouts of swimming." ${ }^{, 71}$ All three 24 hpf end points occurred in a significant number of fish exposed to the AuNPs in this study. At 120 hpf, embryos were evaluated for a second time for mortality along with a suite of other physiological, behavioral, and morphological endpoints. In this study, there were no significant sublethal malformations 
observed at 120 hpf. All experiments were performed in compliance with national care and use guidelines and approved by the Institutional Animal Care and Use Committee (IACUC) at Oregon State University, ACUP \#5114.

\section{Statistical Analyses}

Statistical analyses were performed using Sigma Plot 13.0 (Systat Software, San Jose, CA, USA). Fisher's exact test was used to compare specific developmental endpoints between treatment and controls in the embryonic zebrafish assay. Analysis of variance (ANOVA) was used to evaluate differences among treatment groups across equivalent concentrations. Differences were considered statistically significant at $\mathrm{p} \leq 0.05$ for all analyses.

\section{Results and Discussion}

\section{Preparation and Characterization of Hybrid Lipid-Coated AuNPs}

For this study, hybrid lipid-coated AuNPs were prepared using a previous strategy where AuNPs were coated with SOA and pre-formed liposomes comprised L-a-phosphatidylcholine that are anchored to the AuNP surface with a long-chain hydrophobic thiol. ${ }^{75-77}$ AuNP colloids with diameters of 5,10 , and $20 \mathrm{~nm}$ were coated with hydrogen phosphatidylcholine (HPC), which has two saturated hydrocarbon tails. These diameters were chosen because to represent a range of sizes with unique radius of curvature that can be systematically studied to evaluate their uptake how size and radius of curvature affect interactions with membrane model systems, uptake into cells, and toxicity. The AuNP core, surface chemistry, and charge was kept constant.

To ensure that the HPC membrane was completely covering the NP surface in a tight packing arrangement, a cyanide $\left(\mathrm{CN}^{-}\right)$etch test was performed. $\mathrm{CN}^{-}$is a wellknown etchant of gold and oxidizes $\mathrm{Au}^{0}$ to $\mathrm{Au}^{\mathrm{I}}{ }^{76,78}$ Upon exposure to $\mathrm{CN}^{-}$, the UV-Vis spectra of the hybrid lipidcoated AuNPs after $1 \mathrm{~h}$ showed no change in the localized surface plasmon resonance (LSPR) of the AuNPs (Figure 1) indicating that there is no "bare" patches of gold surface and that the HPC lipid membrane is in a tight packing arrangement that $\mathrm{CN}^{-}$is unable to penetrate through the lipid bilayer for $\mathrm{CN}^{-}$to etch. Resistance to $\mathrm{CN}^{-}$etch was observed for the 5, 10, and $20 \mathrm{~nm}$ and is consistent with previous studies (Figure S2). ${ }^{75,76}$

\section{Stability of Hybrid Lipid-Coated AuNPs}

Since the ultimate target of hybrid lipid-coated AuNPs is for in vitro cellular studies and in vivo embryonic zebrafish studies as well as their potential use in biomedical applications in vivo, their stability in biological media is important. Therefore, stability studies at a range of physiological $\mathrm{pH}$ and ionic strengths with the 5, 10, and $20 \mathrm{~nm} \mathrm{Au-SOA-HPC-HT}$ were performed. In order to standardize our results for comparison of all three sizes, an O.D. of 0.8 was used for all AuNPs. This equated to Au-SOA-HPC-HT concentrations of $4.7 \times 10^{13} \mathrm{nps} / \mathrm{mL}=5 \mathrm{~nm}, 4.7 \times 10^{12} \mathrm{nps} / \mathrm{mL}=10 \mathrm{~nm}$, and $4.7 \times 10^{11} \mathrm{nps} / \mathrm{mL}=20 \mathrm{~nm}$. To evaluate the effect of physiological salt concentrations on the stability of the AuSOA-HPC-HT, samples were exposed to varying $\mathrm{NaCl}$ concentrations ranging from $50 \mathrm{mM}$ to $200 \mathrm{mM}$ and the UV-Vis spectra taken after 1 and $24 \mathrm{~h}$ of incubation. The percent change in the O.D. and $\lambda_{\max }$ was monitored to assess NP aggregation and dipole-dipole coupling. ${ }^{79,80}$ For all Au-SOA -HPC-HT diameters under varying salt concentrations, the percent change in $\lambda_{\max }$ for all hybrid Au-SOA-HPC-HT was $2.5 \%$ or less. More distinct differences were observed with change in O.D. and were used as an indicator of NP stability. Minimal change in O.D. is observed with the $5 \mathrm{~nm}$ $\mathrm{Au}-\mathrm{SOA}-\mathrm{HPC}-\mathrm{HT}$ upon exposure to the $50-200 \mathrm{mM} \mathrm{NaCl}$ concentrations (Figure 2A). The $10 \mathrm{~nm}$ Au-SOA-HPC-HT exhibited a $14 \%$ decrease in O.D. at $1 \mathrm{hr}$ (Figure 2A) and declined further (24\%) after $24 \mathrm{hrs}$ (Figure S3) upon incubation with $200 \mathrm{mM} \mathrm{NaCl}$. A much more significant decrease in the O.D. is observed for the $20 \mathrm{~nm} \mathrm{Au-SOA-HPC-HT} \mathrm{in}$ the presence of 50-200 $\mathrm{mM} \mathrm{NaCl}$ within $1 \mathrm{hr}$ (Figure 2A)

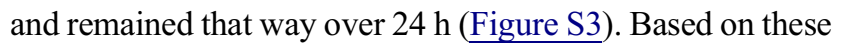

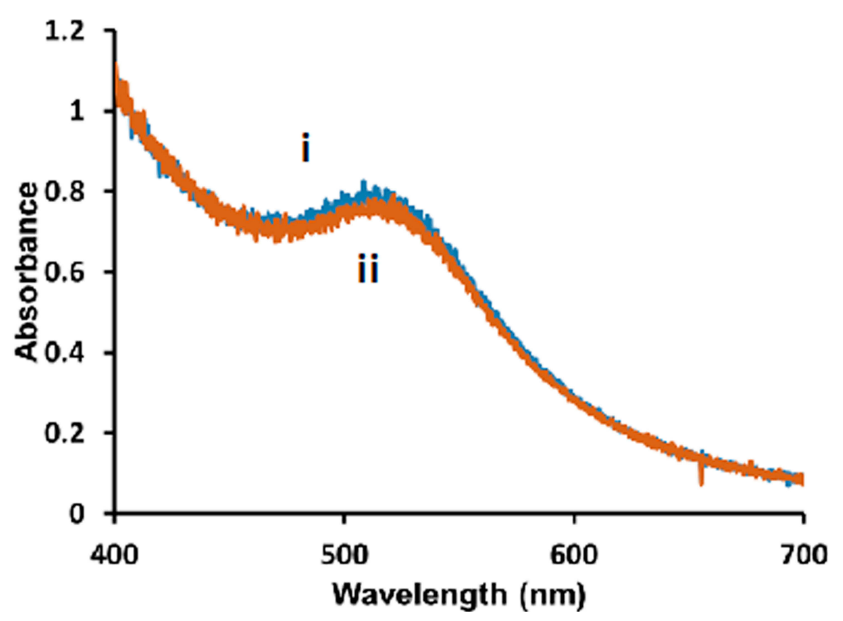

Figure I Representative UV-Vis spectra of $5 \mathrm{~nm}$ diameter Au-SOA-HPC-HT i) before and ii) after the addition of $6.14 \mathrm{mM} \mathrm{KCN}$ for I $\mathrm{h}$ in $\mathrm{H}_{2} \mathrm{O}$. 
changes in O.D. the 5 and $10 \mathrm{~nm}$ Au-SOA-HPC-HT are most stable compared to the $20 \mathrm{~nm}$; however, the amount of salt present relative to the exposed number of NPs present in the solution must be taken into account. That is, the number of 20 $\mathrm{nm}$ NPs per $\mathrm{mL}\left(4.7 \times 10^{11} \mathrm{nps} / \mathrm{mL}\right)$ is less than that of the 5 $\mathrm{nm}\left(4.7 \times 10^{12} \mathrm{nps} / \mathrm{mL}\right)$ and $10 \mathrm{~nm}\left(4.7 \times 10^{11} \mathrm{nps} / \mathrm{mL}\right)$ under the same salt exposure concentrations. In addition, the total number of lipids present in solution is based on the number of nanoparticles present in solution, that aides in increasing solubility and decreasing aggregation, is less for the $20 \mathrm{~nm}$ $<10 \mathrm{~nm}<5 \mathrm{~nm}$. Therefore, $20 \mathrm{~nm}$ Au-SOA-HPC-HT due are exposed to a much higher amount of $\mathrm{Cl}^{-}$in a $1 \mathrm{~mL}$ solution leading more NP-NP interactions than the 5 and 10 $\mathrm{nm}$ NPs. This is confirmed by adjusting the $20 \mathrm{~nm}$ Au-SOAHPC-HT concentrations to have the same number of NPs at the $10 \mathrm{~nm}$ sample at $8.2 \times 10^{11} \mathrm{nps} / \mathrm{mL}$ with an O.D. of 1.4 , the stability of the $20 \mathrm{~nm}$ improved greatly compared to lower concentrations upon exposure to salt for $1 \mathrm{~h}$ and $24 \mathrm{~h}$ (Figure S4). While it is possible that instability can occur from lipid dissociation from the AuNP surface in high salt concentrations, prior studies investigating the robustness of the hybrid lipid-coated AuNPs and silver nanoparticles (AgNPs) confirm that the lipids are arranged in a very tightly packed fashion that is impermeable. ${ }^{76} \mathrm{UV}-\mathrm{Vis}$ and TEM studies that hybrid lipid-coated AuNPs and AgNPs (that is more susceptible to oxidation compared to AuNPs) in the presence of membrane-disrupting surfactants such as TWEEN $^{\circledR} 20$ or Triton-X100 and KCN show that both AuNPs and AgNPs are stable to $\mathrm{CN}^{-}$etch. ${ }^{76}$ This confirms that in the presence of membrane-disrupting surfactants the nanomaterials remain stable and that the lipids do not come off the surface. In addition, upon exposure of citrate-capped
AgNPs and hybrid lipid-coated AgNPs to $50 \mathrm{mM} \mathrm{NaCl}$ and have shown that when the AgNP surface is exposed to AgNP the $\mathrm{Cl}^{-}$induces surface oxidation to citrate-capped AgNPs while no surface oxidation is observed with hybrid lipidcoated AgNPs as confirm by UV-Vis and ICP-MS measuring $\mathrm{Ag}^{+}$ion release. ${ }^{81}$ The hybrid lipid-coated AuNP and AgNPs are stable in the presence of $\mathrm{CN}^{-}$and $\mathrm{Cl}^{-}$for months as confirmed by ICP-MS. ${ }^{76,81}$ Lastly, since in this study, the AuSOA-HPC-HT NPs will be exposed to zebrafish embryos the stability was also evaluated and monitored in fish water (FW). Au-SOA-HPC-HT mixed with the FW in a 1:1 ratio are found to be relatively stable in the FW media as indicated by the minimal change in the O.D. (Figure S5). This is as expected since the fish water solution is at a neutral $\mathrm{pH}$ and its salinity is minimal. Overall, hybrid lipid-coated AuNPs are stable under physiological concentrations of salts and in FW.

It is well known that nanomaterials are taken up into cells into lysosomal compartments where the $\mathrm{pH}$ is 5 and cellular level interactions can induce changes in the physicochemical properties of the NPs, changes physiological structure of the cell and its behavior, and toxicity. ${ }^{82-85}$ To evaluate the stability of the AuNPs under varying $\mathrm{pH}$ conditions, the acidity was adjusted with $2 \mathrm{M} \mathrm{HCl}$ (aq) and the change in O.D. was monitored by UV-Vis spectroscopy. All diameters of Au-SOA-HPC-HT are stable at $\mathrm{pH}$ 8.0, as was expected, since the HPC head group remains in its zwitterionic form suspending the AuNPs in aqueous solution (data not shown). Reducing the $\mathrm{pH}$ to 5 did not have a significant effect on the stability of the $5 \mathrm{~nm}$ hybrid NPs. However, after $1 \mathrm{~h}$, at $\mathrm{pH} 5$ and $\mathrm{pH} 2$, the $10 \mathrm{~nm}$ and $20 \mathrm{~nm}$ HPC-AuNPs aggregated and there is a lost in
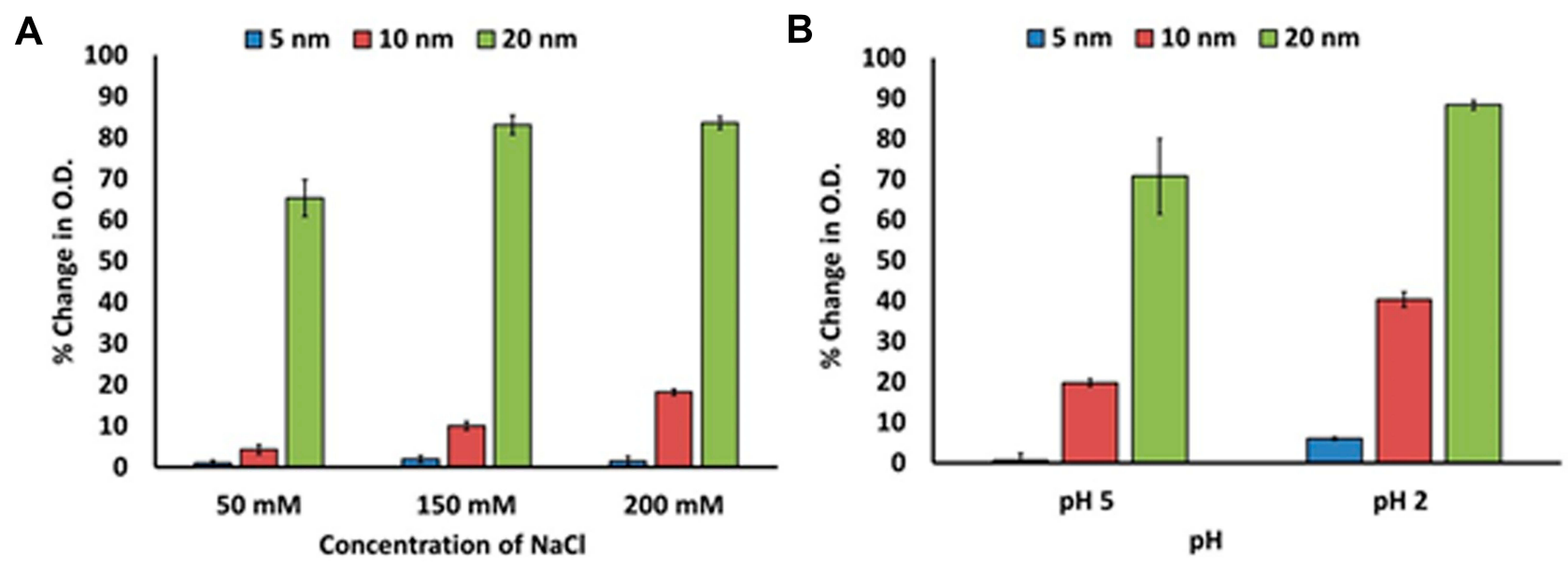

Figure 2 Percent change in O.D. of hybrid lipid capped Au-SOA-HPC-HT in $10 \mathrm{mM}$ sodium phosphate buffer pH $8.0 \mathrm{I}$ h after (A) exposure to $50 \mathrm{mM}$, I50 mM, or $200 \mathrm{mM}$ $\mathrm{NaCl}(\mathrm{aq})$ and $(\mathbf{B})$ adjustment of $\mathrm{pH}$ to 2 and 5 with $2 \mathrm{M} \mathrm{HCl}$. Data mean $\pm \mathrm{SE}$ reported for $\mathrm{n}=3$. 
stability as evidenced by the significant decrease in O.D. (Figure 2B). A much higher ratio of $\mathrm{H}^{+}$ions to available lipids on the 10 and $20 \mathrm{~nm}$ Au-SOA-HPC-HT is present and protonates the $\mathrm{PC}$ headgroups to neutral charge to cause aggregation. This loss in stability is much more noticeable at $\mathrm{pH} 2$ where $40 \%$ and $88 \%$ decrease in $\mathrm{O}$. D. is observed for 10 and $20 \mathrm{~nm}$ Au-SOA-HPC-HT, respectively. Regardless of aggregation, the hybrid lipid membrane anchored to the AuNPs remains intact to shield the surface of the AuNPs as no shift in the LSPR band is observed. These studies help to elucidate how the behavior in their media might influence cellular uptake and toxicity.

\section{Lipid Monolayer Interactions}

Insight into how a cell membrane lipid interface responds to the presence of AuNPs of various sizes can be gained by collecting SFG spectra at a NP-lipid interface. SFG has been used to study how DNA, ${ }^{86}$ proteins, ${ }^{35}$ and $\mathrm{NPs}^{54}$ manipulate lipid membranes. Previous investigations of NP-lipid interactions indicate that NP size and coating dictate the mechanism by which the particles transport themselves through a lipid interface. Recent characterizations of interactions between a lipid bilayer and spherical citrate-coated AuNPs of different sizes demonstrate with SFG that for all sizes flip-flopping of the lipids that made up the bilayer always occurred. ${ }^{87}$ Where the lipid "flipflop" describes a process undertaken by the cell for a variety of processes including apoptosis, viral infection, and membrane growth. The flip-flop observed in SFG experiments induced by NPs at a lipid interface represents the penetration of the particle through a cell membrane. ${ }^{88}$ While an additional investigation using SFG showed that AuNPs with a specific charge or coating can induce lipid conformation around the particle. ${ }^{55}$ The idea of a lipid membrane wrapping around a particle is supported by other work examining NP uptake by cells. ${ }^{89,90}$ This body of work implies that factors such as size and coating, directly influence particle-lipid interactions.

To identify how the structure of the lipid monolayer is affected by the presence of Au-SOA-HPC-HT, SFG spectra were taken before and after the AuNPs were injected under a model lipid monolayer. Similar experimental setups have been described elsewhere. ${ }^{35,87,91}$ All the spectra contain features related to C-D vibrational modes within the deuterated lipids (Figures 3 and 4). ${ }^{35,92,93}$ Assignments and fits for each spectral feature can be found in (Table S2-4). The deuterated $\mathrm{dDPPC}$ allows us to isolate the carbon species within the lipid monolayer from the non-deuterated DPPC on the NPs. In this study changes in the peaks related to the symmetric $\mathrm{CD}_{2}$ stretch at $2100 \mathrm{~cm}^{-1}$ and asymmetric $\mathrm{CD}_{2}$ stretches present at $2202 \mathrm{~cm}^{-1}$ provide insight into the structure of lipid tails at the air/water interface. Specifically, changes in the $\mathrm{CD}_{2}$ peak height indicate a shift in the packing of the lipid monolayer. Therefore, variations of the intensities of the $\mathrm{CD}_{2}$ vibrational modes were measured before and after NP injection. For a monolayer in a LC state, the acyl chains of the lipid will be packed tightly resulting in an all-trans conformation. In this case, signal generated from the $\mathrm{CD}_{2}$ vibrational modes, will cancel each other out, leading to no observable SFG signal. Consequently, with a less ordered monolayer, the acyl chains no longer pack as tightly and are free to move, leading to gauche defects; therefore, the intensity of the $\mathrm{CD}_{2}$ peak within the resulting SFG spectrum will become more prominent. Changes in the $\mathrm{CD}_{2}$ peak height after NP injection gives insight into the mechanism by which the AuNPs interact at the lipid interface.

Interactions between the 5 and $10 \mathrm{~nm}$ AuNPs and dDPPC lipids show the same response, no matter the initial packing density (LC and LC+LE states) (Figure 3). Each of the lipid monolayers are packed together more tightly after AuNP injection. This is confirmed by the intensity of the $\mathrm{CD}_{2}$ peaks in the SFG spectra (Figure 3). In the case of $5 \mathrm{~nm}$ and $10 \mathrm{~nm}$ AuNPs there is an observed reduction in the $\mathrm{CD}_{2}$ peak at $2100 \mathrm{~cm}^{-1}$ following the injection of AuNPs (Figure 3A and B). The change shows that the lipids in the monolayer are being pushed together because the $\mathrm{CD}_{2}$ peak

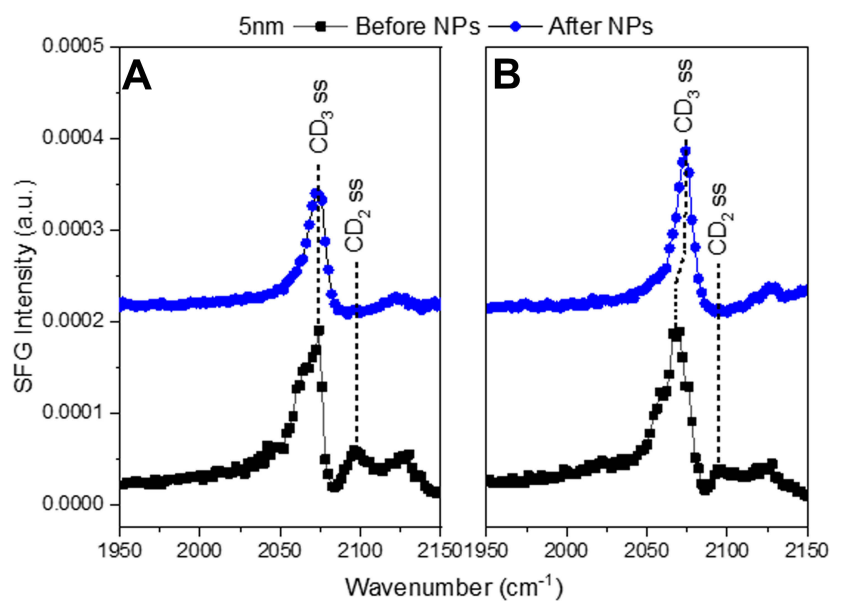

Figure 3 SFG spectra in the CD region of (A) LC+LE monolayer and (B) a LC monolayer before and after the injection of $5 \mathrm{~nm}$ AuNPs. The black squares show the lipid monolayer before NPs were injected. The blue circles show the lipid monolayer and NP interaction after $4 \mathrm{~h}$. The symmetric $\mathrm{CD}_{3}$ stretch is at $2075 \mathrm{~cm}^{-1}$ with the symmetric $C D_{2}$ stretch at $2100 \mathrm{~cm}^{-1}$. The symmetric $C D_{2}$ peak disappears after NP injection for both LC (A) and LC+LE (B) monolayers indicating the NPs pushed the lipid tails into a trans conformation. 


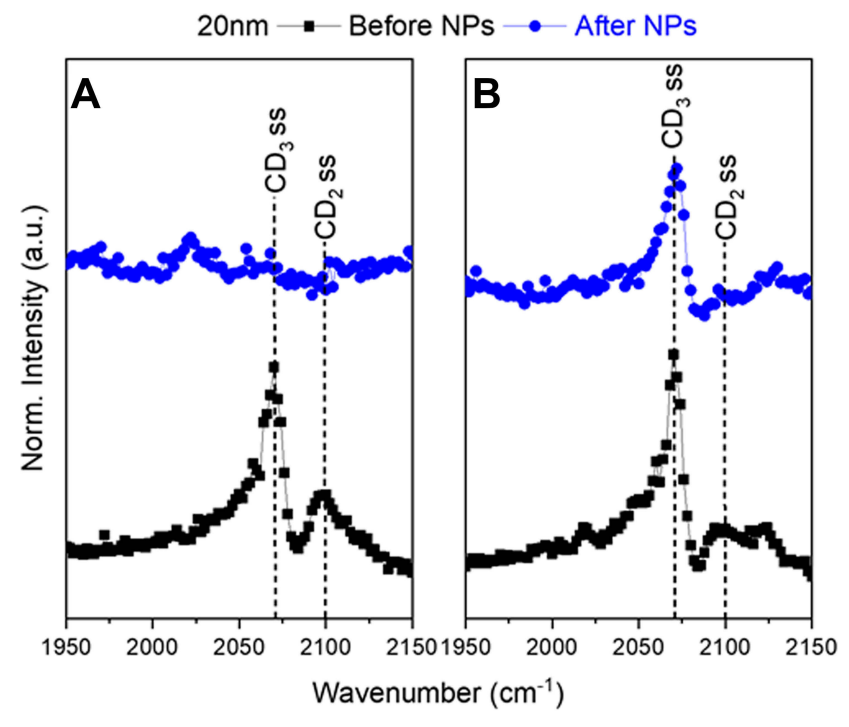

Figure 4 Representative SFG spectra in the CD region of $(\mathbf{A})$ with a LC+LE monolayer and (B) with a LC monolayer. The black squares show the lipid monolayer before $20 \mathrm{~nm}$ NPs were injected. The blue circles show the lipid monolayer and NP interaction after four hours. The symmetric $C_{3}$ stretch is at $2075 \mathrm{~cm}^{-1}$ with the symmetric $C D_{2}$ stretch at $2100 \mathrm{~cm}^{-1}$. The $L C$ (A) monolayer SFG signal disappeared indicating a collapse of the lipid monolayer. In the LC+LE (B) monolayer the small $C D_{2}$ peak shows an intact monolayer. These spectra exhibit the difference the initial monolayers have on AuNP-lipid interactions.

has disappeared. In this study, the binding of 5 and $10 \mathrm{~nm}$ AuNPs to the lipids, in both the LC and LC+LE states, adopted an increasingly trans conformation shown in the reduction of the $\mathrm{CD}_{2}$ peak at $2100 \mathrm{~cm}^{-1}$ (Figure 3). When lipids adopt a greater degree of trans conformation, this indicates a compression of the lipid monolayer. ${ }^{38}$ This observation implies that the NP inserts itself into the lipid monolayer. Effectively pushing the lipids closer together similar to the "snorkel" effect observed in Monte Carlo simulations assessing free energy changes of lipid penetration. ${ }^{94}$ The same simulation shows the lowest energy barrier for the "snorkeling" of a spherical AuNPs with a diameter slightly below $5 \mathrm{~nm}$, in agreement with observed SFG spectra. In contrast, the $20 \mathrm{~nm}$ AuNPs $\mathrm{CD}_{2}$ peak either remained or disappeared after AuNP injection (Figure 4). Compared to the smaller sized particles, the $20 \mathrm{~nm}$ AuNPs exhibit a different interaction with the lipid monolayers. Additionally, the lipid response to the $20 \mathrm{~nm}$ AuNPs is dependent on the lipid packing density of the monolayer. For the $\mathrm{LC}+\mathrm{LE}$ monolayer, there is a lack of $\mathrm{CD}_{2}$ or $\mathrm{CD}_{3}$ at $2100 \mathrm{~cm}^{-1}$ and $2075 \mathrm{~cm}^{-1}$ peaks, respectively, after NP injection shown in (Figure 4A). This lack of SFG signal in the less dense layer, after AuNP injection, at these vibrational modes is likely due to the collapse of the lipid monolayer, producing a random ordering of the lipids within the monolayer. However, this is not the case for the denser lipid monolayer, where the $\mathrm{CD}_{3}$ and $\mathrm{CD}_{2}$ peaks at $2075 \mathrm{~cm}^{-1}$ and $2100 \mathrm{~cm}^{-1}$ are still present within SFG spectra collected as the $20 \mathrm{~nm}$ AuNPs interact with the LC monolayer (Figure 4B). Thereby, implying that the LC monolayer remains intact in the presence of the $20 \mathrm{~nm}$ AuNPs. The $\mathrm{CH}$ vibrational modes provide more information on the lipid response to the AuNPs because only the tails of the lipid are deuterated.

The $\mathrm{CH}$ region is used to probe stretches on the head group of the lipids at the AuNP surface (Figure S1). The head group of the lipids are not deuterated, the CD vibrational modes come from the tails only. The SFG spectra showed two distinct modes visible near 2913 and $2963 \mathrm{~cm}^{-1}$ assigned to the asymmetric stretches of the methyl and methylene groups of the lipids and other ligands on the AuNP surface (Figures 5 and 6). ${ }^{86,92,93,95,96}$ A similar response has also been observed by $\mathrm{Ma}$ and Allen et al with the same lipids. ${ }^{38}$ Symmetric stretches were present with comparably low signals for the lipid monolayer and AuNPs. ${ }^{38}$ With only asymmetric stretches being noticeable, it is likely that the headgroup of the lipids, the source of the $\mathrm{CH}$ signal for dDPPC, lie closer to the surface than the surface normal. ${ }^{97,98}$ This is due to the stretches that can be observed in the $s s p$ polarization combination. If the plane of symmetry for the methyl group lies parallel to the surface, only the asymmetric stretches will be observed. It is important to also note that observation of the head group orientation is not dependent on the degree of packing density for the lipid monolayer. $^{38}$ This is in contrast to lipid tails, whose orientation becomes more uniform with increasing packing densities.

Analysis of the SFG spectra shows that the 5 and $10 \mathrm{~nm}$ AuNPs push their way into the LC+LE monolayer, where the $20 \mathrm{~nm}$ AuNPs are large enough collapse it. The $\mathrm{CH}$ spectra confirm the presence of AuNPs at the interface and that this collapse only occurs because of the AuNPs. Of the three AuNPs used in this study, the $20 \mathrm{~nm}$ AuNP was the only one dependent on the initial state of the lipid monolayer for its interaction. It either binds to the monolayer, inducing curvature, keeping it intact or sufficiently disrupts the monolayer to cause disorder. While the high curvature 5 and $10 \mathrm{~nm}$ NPs induce the same lipid response, pushing the lipids that make up the monolayer closer together, implying that both "snorkel" through the layer.

The collection of SFG spectra indicates that size is an important factor for NP penetration as evidenced by the different responses observed when comparing the 5 and 10 


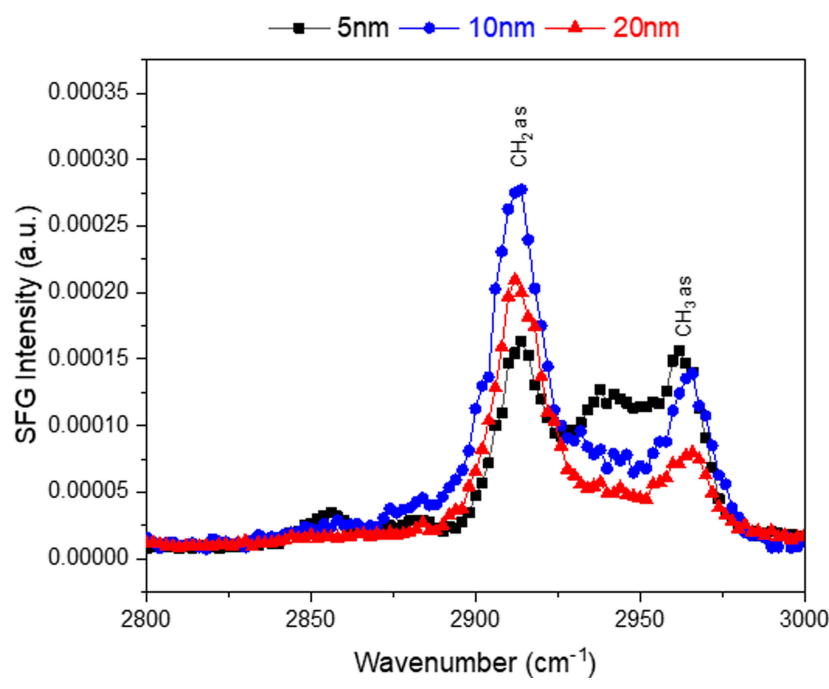

Figure 5 SFG spectra showing the $\mathrm{CH}$ region for each of the 5, 10, $20 \mathrm{~nm}$ Au-SOA -HPC-HT. The NPs are at an air/water interface free of any lipids. The $\mathrm{CH}_{2}$ asymmetric stretch is at $2913 \mathrm{~cm}^{-1}$ with the $\mathrm{CH}_{3}$ asymmetric stretch at $2963 \mathrm{~cm}^{-1}$. The NPs exhibit only asymmetric stretches which indicates strong ordering of the lipid coating.

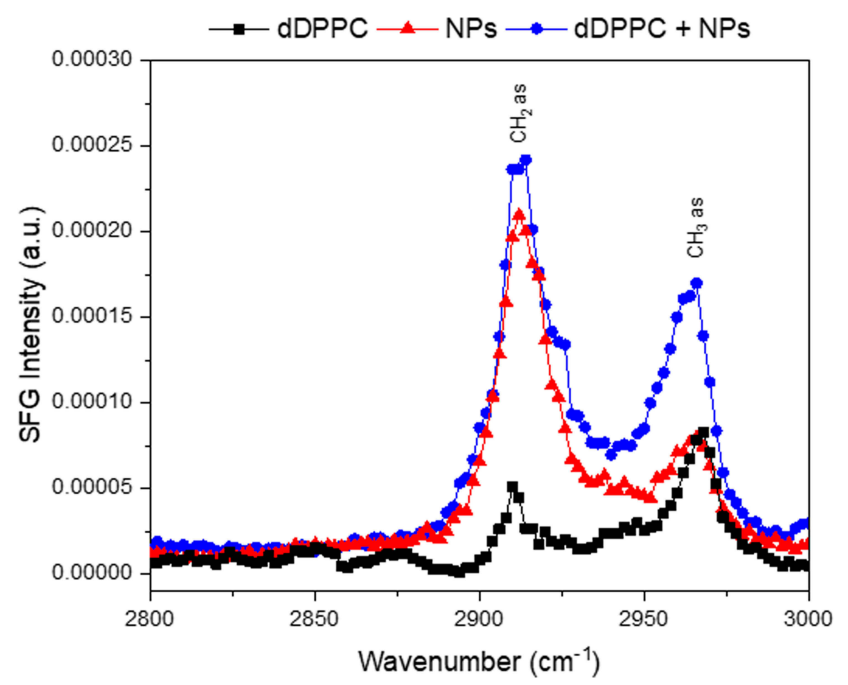

Figure 6 Representative SFG spectra showing the $\mathrm{CH}$ region for the lipid monolayer, $20 \mathrm{~nm}$ Au-SOA-HPC-HT and the NP-dDPPC lipid interface. The black squares correspond to only the lipid monolayer at the air/water interface. The red triangles correspond to only the Au-SOA-HPC-HT. The blue circles correspond to the interaction of NPs and the lipid monolayer at the surface after $4 \mathrm{hrs}$. The $\mathrm{CH}_{2}$ asymmetric stretch is at $2913 \mathrm{~cm}^{-1}$ with the $\mathrm{CH}_{3}$ asymmetric stretch at $2963 \mathrm{~cm}^{-1}$. The spectra show that NPs are at the NP-dDPPC interface and responsible for the observed structural changes in the lipid monolayer.

nm AuNPs to the $20 \mathrm{~nm}$ AuNPs (Figures 3 and 4). In the LC monolayer, there are changes in the $\mathrm{CD}$ vibrational modes $\left(\mathrm{CD}_{3}\right.$ and $\mathrm{CD}_{2}$ ) (Figure $4 \mathrm{~A}$ ) after the $20 \mathrm{~nm}$ NPs have been injected. Indicating that the lipid monolayer's packing has an impact on the response to larger AuNPs. Shown in the LC monolayer where the lipids are packed tightly enough to resist the $20 \mathrm{~nm}$ NP from "snorkeling" into the monolayer. The interaction between the $20 \mathrm{~nm} \mathrm{NP}$ and the lipid monolayer is kept intact, evident from the remaining CD signal (Figure 4B). This binding induces a curvature of the monolayer while holding together the structure of the monolayer. The idea of a lipid monolayer curving around a NP is supported by an atomistic simulation where a negatively charged NP, absent of any coating, induces curvature of a DPPC membrane through gains in electrostatic energy at the loss of elastic energy. ${ }^{99}$ The integrity of the lipid monolayer when interacting with 20 $\mathrm{nm}$ AuNPs is dependent on the initial degree of packing in the monolayer. With the LC+LE monolayer, there was a lack of signal and no distinguishable vibrational modes in the CD region after $20 \mathrm{~nm}$ NP injection. This shows that the $20 \mathrm{~nm}$ AuNPs have broken the non-centrosymmetric environment leading to a disordering effect on the lipids. In the LC+LE monolayer the lipids are more loosely packed and the $20 \mathrm{~nm}$ AuNP is now able to "snorkel" into the monolayer but causes a significant enough disruption to disorder the lipids at the interface. Consistent with the lack of SFG signal observed in (Figure 4A), this is in contrast to "snorkel" behavior with the 5 and $10 \mathrm{~nm}$ AuNPs.

\section{Toxicity Studies}

In vivo Embryonic Zebrafish Toxicity

Embryonic zebrafish were exposed individually to each of the AuNPs at concentrations ranging from $2.5 \mathrm{mg} / \mathrm{L}$ to $50 \mathrm{mg} / \mathrm{L}$. Mortality is observed at both $24 \mathrm{hpf}$ (Figure 7A) and at $120 \mathrm{hpf}$ (Figure 7B). Significant mortality is observed in zebrafish exposed to the $5 \mathrm{~nm}$ AuNPs at concentrations higher than $20 \mathrm{mg} / \mathrm{L}$ starting at $24 \mathrm{hpf}$. Due to the rapid development of the zebrafish during the first $24 \mathrm{~h}$ window, the trends in mortality become less clear at concentrations greater than $20 \mathrm{mg} / \mathrm{L}$. The variations in individual embryo development during this window account for the large error bars in their mortality response. A similar mortality trend was observed at $120 \mathrm{hpf}$, with significant $120 \mathrm{hpf}$ mortality observed in the zebrafish exposed to concentrations of $20 \mathrm{mg} / \mathrm{L}$ or greater of the $5 \mathrm{~nm}$ AuNPs. No significant mortality is observed in either the $10 \mathrm{~nm}$ or $20 \mathrm{~nm}$ AuNPs at either of the $24 \mathrm{hpf}$ or the $120 \mathrm{hpf}$ time points.

Aside from mortality, three significant sublethal malformations are observed at $24 \mathrm{hpf}$. Malformations in the notochord delayed developmental progression and impacts on spontaneous movement may be predictive of teratogenic outcomes at $120 \mathrm{hpf}^{100}$ Significant sublethal malformations are observed at $24 \mathrm{hpf}$ in the $5 \mathrm{~nm}$ and $10 \mathrm{~nm}$ AuNPs (Figure 8A and B). No significant malformations 
are observed in the zebrafish exposed to the $20 \mathrm{~nm}$ AuNPs (Figure $8 \mathrm{C}$ ). There are no significant sublethal endpoints observed at $120 \mathrm{hpf}$, only mortality.

The significant mortality and morbidity observed at 24 hpf in the embryonic zebrafish exposed to the $5 \mathrm{~nm}$ AuNPs further substantiates the rapid insertion and uptake of the Au-SOA-HPC-HT due to minimal-free energy cost. This minimal-free energy cost is believed to allow for rapid uptake into cells and may contribute to the increased toxicity observed. The $10 \mathrm{~nm}$ AuNPs elicited moderate morbidity at $24 \mathrm{hpf}$ and no mortality at $120 \mathrm{hpf}$ indicating some uptake and minor developmental effects. The largest, $20 \mathrm{~nm}$ AuNPs, elicited no mortality or morbidity at $24 \mathrm{hpf}$ or $120 \mathrm{hpf}$, indicating very little uptake of the particles. Others have showed similar size-dependent toxicity patterns of AuNPs. ${ }^{23-25}$

We believe that when coated with a lipid bilayer, smaller AuNPs with high radius of curvature will phase through cell membranes, whereas larger $(>10 \mathrm{~nm})$ AuNPs with low radius of curvature have to be endocytosed into cells. This is
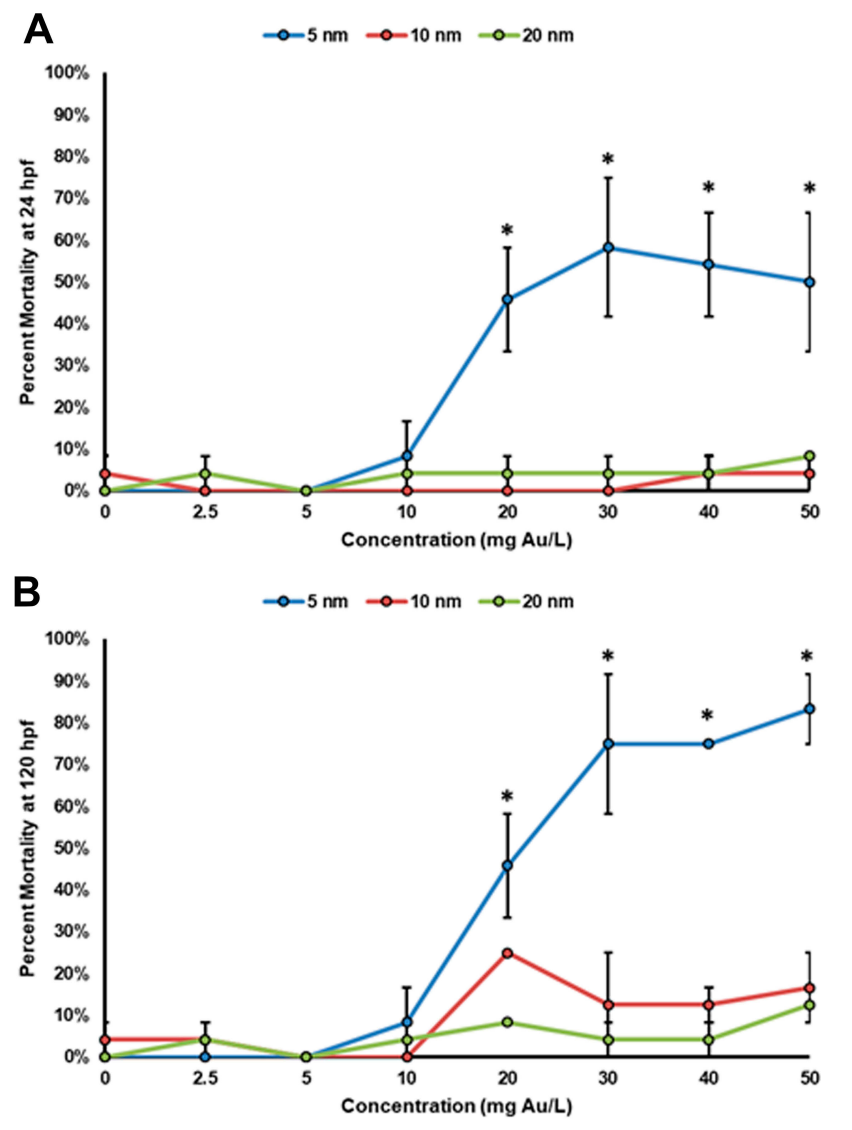

Figure 7 Concentration-response curves of zebrafish mortality at (A) $24 \mathrm{hpf}$ and (B) $120 \mathrm{hpf}$. This data represents two experimental replicates of $n=12$ for a total of $n=24$ for each exposure condition. *Indicates significant difference from control by a Fisher's exact test ( $p$-value $<0.05$ ). demonstrated through the differential ordering and interactions of the dPPC lipids with the AuNPs at the air-water interface, imaged in vitro in human kidney cells, and shown in vivo in embryonic zebrafish toxicity tests. These findings and proposed mechanism of action are consistent with simulations ${ }^{94}$ and studies of other NPs, ${ }^{101}$ leading to the belief that this is a viable mechanism of uptake and toxicity. It would be beneficial to further assess the size-dependent interactions of AuNPs by utilizing larger and smaller particles tested to further confirm the proposed mechanism.

A

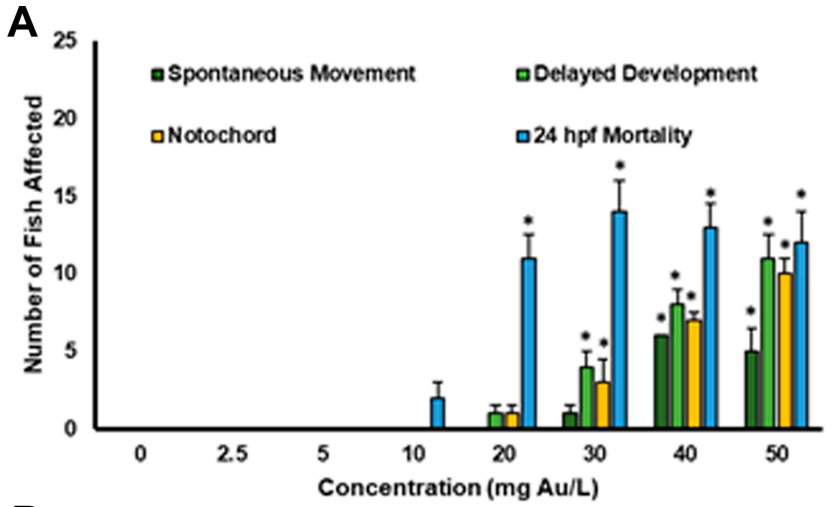

B
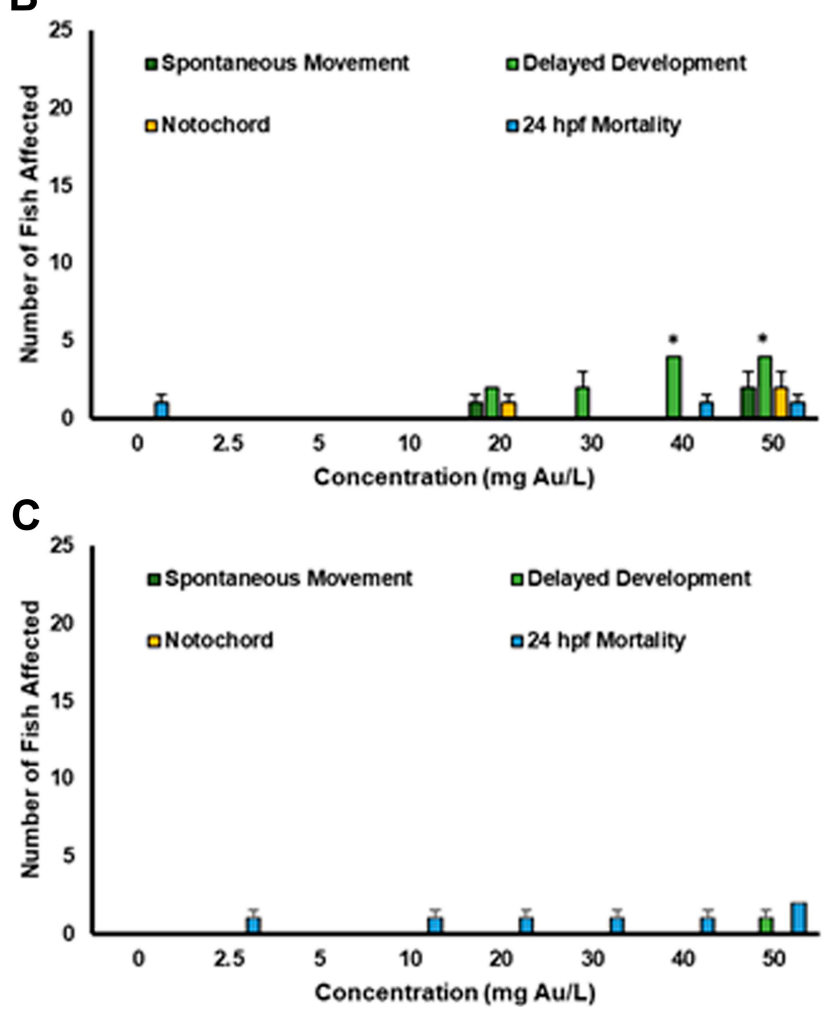

Figure 8 Malformations assessed at 24 hpf show delayed developmental progression, notochord malformations, and effects on spontaneous movement in the zebrafish exposed to the (A) $5 \mathrm{~nm}$, (B) $10 \mathrm{~nm}$, and (C) $20 \mathrm{~nm}$ AuNPs. This data represents two experimental replicates of $n=12$ for a total of $n=24$ for each exposure condition. *Indicates significant difference from control by a Fisher's exact test $(p$-value $<0.05)$. 

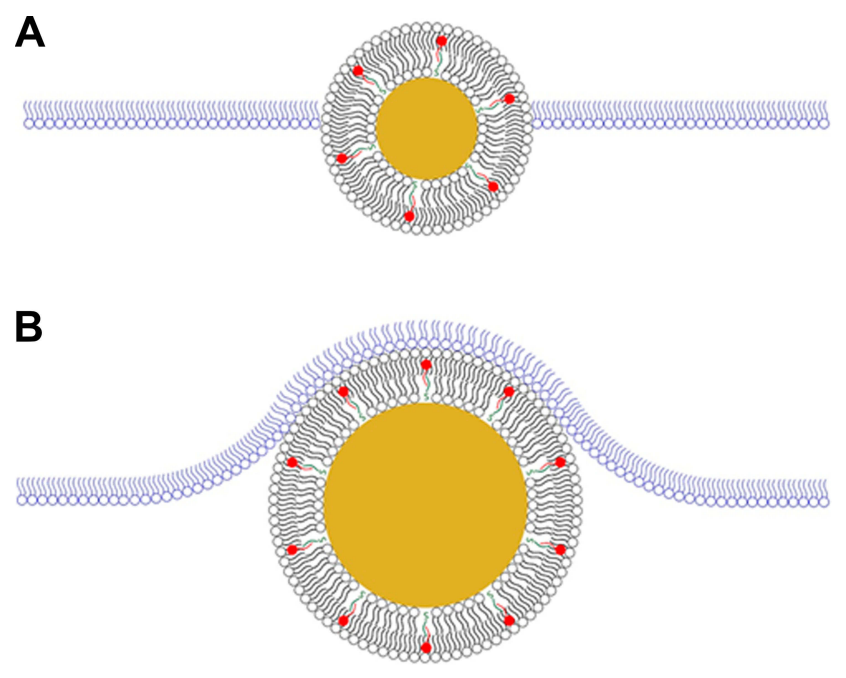

Figure 9 Proposed size-dependent interactions between hybrid lipid-coated AuNPs and biomimetic lipid monolayer. The $5 \mathrm{~nm}$ and $10 \mathrm{~nm}$ AuNPs were able to phase into the membrane (A) whereas the $20 \mathrm{~nm}$ AuNPs induced curvature of the membrane (B). AuNP membranes composed of hPC (black) and SOA (red) are anchored to the surface with HT (green). The lipid monolayer is composed of dDPPC (blue).

\section{Conclusion}

The size-dependent behavior of AuNPs is well understood in the literature. AuNPs of varying sizes display greatly different biouptake, biodistribution, excretion, and ultimately toxicity. Many mechanisms of cellular uptake, toxicity, and membrane interaction have been proposed independently, but never investigated systematically together. Here, the size-dependent interactions of AuNPs were assessed using a suite of NPs with wellcontrolled surface coatings and sizes across various levels of biological complexity. AuNP interactions with a biomimetic lipid monolayer measured using SFG highlighted the size-dependent nature of the NPs. The SFG measurements showed that the $5 \mathrm{~nm}$ and $10 \mathrm{~nm}$ AuNPs with high radius of curvature are able to phase into the membrane (Figure 9A), due to low energetic cost to do so, whereas the largest, $20 \mathrm{~nm}$ AuNP, induced curvature of the lipid monolayer (Figure 9B). In vitro, human embryonic kidney cells exposed to AuNPs showed no significant difference in viability across any concentrations tested. TEM imaging confirmed no interaction or uptake of the AuNPs into the cells, potentially due to the lipid-bilayer surface coating on the AuNPs preventing interaction with this specific cell type. In vivo, the rapid uptake of the $5 \mathrm{~nm}$ AuNPs confirms that these NPs inflict significant mortality and morbidity at $24 \mathrm{hpf}$ in embryonic zebrafish. The $20 \mathrm{~nm}$ AuNPs showed no significant mortality or morbidity at $24 \mathrm{hpf}$ nor at $120 \mathrm{hpf}$, confirming their less energetically favorable, slower uptake into cells. Intermediate to both the $5 \mathrm{~nm}$ and $20 \mathrm{~nm}$ AuNPs the $10 \mathrm{~nm}$ AuNPs showed moderate morbidity at $24 \mathrm{hpf}$ but no mortality or morbidity at $120 \mathrm{hpf}$. Assessing the sizedependent nature of AuNPs at three different levels of biological complexity gives much greater insight into the interactions and mechanisms that may be driving their toxicity.

\section{Acknowledgments}

The first batches of gold nanomaterials were hybridized by Hamzah Sawab in Dr. Marilyn Mackiewicz's lab at Portland State University. This work was supported by grants: NSF: \#1905091 and NIH: \#1 R21 HD096301-01.

\section{Disclosure}

Dr Marilyn R Mackiewicz reports a patent Hybrid Membrane-Coated Nanoparticle Composites and Methods of Making and Using the Same US Patent 16/127013 filed 9-10-2018 pending. The authors report no other conflicts of interest in this work.

\section{References}

1. Bobo D, Robinson KJ, Islam J, Thurecht KJ, Corrie SR. Nanoparticlebased medicines: a review of FDA-approved materials and clinical trials to date. Pharm Res. 2016;33(10):2373-2387. doi:10.1007/ s11095-016-1958-5

2. Caster JM, Patel AN, Zhang T, Wang A. Investigational nanomedicines in 2016: a review of nanotherapeutics currently undergoing clinical trials. Wiley Interdiscip Rev Nanomed Nanobiotechnol. 2017;9(1):e1416.

3. Min Y, Caster JM, Eblan MJ, Wang AZ. Clinical translation of nanomedicine. Chem Rev. 2015;115(19):11147-11190. doi:10.1021/ acs.chemrev. 5 b00116

4. Adnan NN, Cheng Y, Ong NM, et al. Effect of gold nanoparticle shapes for phototherapy and drug delivery. Polym Chem. 2016;7 (16):2888-2903. doi:10.1039/C6PY00465B

5. Von Maltzahn G, Park J-H, Agrawal A, et al. Computationally guided photothermal tumor therapy using long-circulating gold nanorod antennas. Cancer Res. 2009;69(9):3892-3900. doi:10.1158/00085472.CAN-08-4242

6. Huang X, Jain PK, El-Sayed IH, El-Sayed MA. Plasmonic photothermal therapy (PPTT) using gold nanoparticles. Lasers Med Sci. 2008;23 (3):217. doi:10.1007/s10103-007-0470-x

7. El-Sayed IH, Huang X, El-Sayed MA. Selective laser photo-thermal therapy of epithelial carcinoma using anti-EGFR antibody conjugated gold nanoparticles. Cancer Lett. 2006;239(1):129-135. doi:10.1016/j. canlet.2005.07.035

8. Hainfeld JF, Slatkin DN, Smilowitz HM. The use of gold nanoparticles to enhance radiotherapy in mice. Phys Med Biol. 2004;49(18):N309. doi:10.1088/0031-9155/49/18/N03

9. Park H, Lim D-J, Vines JB, Yoon J-H, Ryu N-E. Gold Nanoparticles for Photothermal Cancer Therapy. Front Chem. 2019;7:167. doi: $10.3389 /$ fchem. 2019.00167 
10. Paciotti GF, Myer L, Weinreich D, et al. Colloidal gold: a novel nanoparticle vector for tumor directed drug delivery. Drug Deliv. 2004;11(3):169-183. doi:10.1080/10717540490433895

11. Champion JA, Katare YK, Mitragotri S. Particle shape: a new design parameter for micro-and nanoscale drug delivery carriers. $J$ Controlled Release. 2007;121(1-2):3-9.

12. Men W, Zhu P, Dong S, et al. Fabrication of dual ph/redox-responsive lipid-polymer hybrid nanoparticles for anticancer drug delivery and controlled release. Int $J$ Nanomedicine. 2019;14:8001. doi:10.2147/IJN.S226798

13. Dreaden EC, Mackey MA, Huang X, Kang B, El-Sayed MA. Beating cancer in multiple ways using nanogold. Chem Soc Rev. 2011;40(7):3391-3404. doi:10.1039/c0cs00180e

14. Conde J, Ambrosone A, Sanz V, et al. Design of multifunctional gold nanoparticles for in vitro and in vivo gene silencing. ACS Nano. 2012;6(9):8316-8324. doi:10.1021/nn3030223

15. Min Y, Mao CQ, Chen S, Ma G, Wang J, Liu Y. Combating the drug resistance of cisplatin using a platinum prodrug based delivery system. Angew Chem Int Ed. 2012;51(27):6742-6747. doi:10.1002/anie.201201562

16. Wang F, Wang Y-C, Dou S, Xiong M-H, Sun T-M, Wang J. Doxorubicin-tethered responsive gold nanoparticles facilitate intracellular drug delivery for overcoming multidrug resistance in cancer cells. ACS Nano. 2011;5(5):3679-3692. doi:10.1021/nn200007z

17. Barenholz YC. Doxil ${ }^{\circledR}$ — the first FDA-approved nano-drug: lessons learned. $J$ Controlled Release. 2012;160(2):117-134. doi:10.1016/j.jconrel.2012.03.020

18. Connor EE, Mwamuka J, Gole A, Murphy CJ, Wyatt MD. Gold nanoparticles are taken up by human cells but do not cause acute cytotoxicity. Small. 2005;1(3):325-327. doi:10.1002/smll.200400093

19. Elci SG, Jiang Y, Yan B, et al. Surface charge controls the suborgan biodistributions of gold nanoparticles. ACS Nano. 2016;10(5):5536-5542. doi:10.1021/acsnano.6b02086

20. Wang J-Y, Chen J, Yang J, et al. Effects of surface charges of gold nanoclusters on long-term in vivo biodistribution, toxicity, and cancer radiation therapy. Int $J$ Nanomedicine. 2016;11:3475. doi: $10.2147 /$ IJN.S106073

21. Harper B, Sinche F, Ho Wu R, et al. The impact of surface ligands and synthesis method on the toxicity of glutathione-coated gold nanoparticles. Nanomaterials. 2014;4(2):355-371. doi:10.3390/ nano4020355

22. Patlolla AK, Kumari SA, Tchounwou PB. A comparison of poly-ethylene-glycol-coated and uncoated gold nanoparticle-mediated hepatotoxicity and oxidative stress in Sprague Dawley rats. Int J Nanomedicine. 2019;14:639. doi:10.2147/IJN.S185574

23. Carnovale C, Bryant G, Shukla R, Bansal V. Identifying trends in gold nanoparticle toxicity and uptake: size, shape, capping ligand, and biological corona. ACS Omega. 2019;4(1):242-256. doi:10.1021/acsomega.8b03227

24. Pan Y, Neuss S, Leifert A, et al. Size-dependent cytotoxicity of gold nanoparticles. Small. 2007;3(11):1941-1949. doi:10.1002/ smll.200700378

25. Coradeghini R, Gioria S, Garcia CP, et al. Size-dependent toxicity and cell interaction mechanisms of gold nanoparticles on mouse fibroblasts. Toxicol Lett. 2013;217(3):205-216. doi:10.1016/j. toxlet.2012.11.022

26. $\mathrm{Li} \mathrm{X}, \mathrm{Hu} \mathrm{Z}$, Ma J, et al. The systematic evaluation of size-dependent toxicity and multi-time biodistribution of gold nanoparticles. Colloids Surf B Biointerfaces. 2018;167:260-266. doi:10.1016/j.colsurfb.2018.04.005

27. Mironava T, Hadjiargyrou M, Simon M, Jurukovski V, Rafailovich MH. Gold nanoparticles cellular toxicity and recovery: effect of size, concentration and exposure time. Nanotoxicology. 2010;4(1):120-137. doi:10.3109/17435390903471463
28. Hou W-C, Moghadam BY, Corredor C, Westerhoff P, Posner JD. Distribution of functionalized gold nanoparticles between water and lipid bilayers as model cell membranes. Environ Sci Technol. 2012;46(3):1869-1876. doi:10.1021/es203661k

29. Simko M, Nosske D, Kreyling WG. Metrics, dose, and dose concept: the need for a proper dose concept in the risk assessment of nanoparticles. Int $J$ Environ Res Public Health. 2014;11 (4):4026-4048. doi:10.3390/ijerph110404026

30. Rushton EK, Jiang J, Leonard SS, et al. Concept of assessing nanoparticle hazards considering nanoparticle dosemetric and chemical/biological response metrics. J Toxicol Environ Health A. 2010;73(5):445-461. doi:10.1080/15287390903489422

31. Wittmaack K. In search of the most relevant parameter for quantifying lung inflammatory response to nanoparticle exposure: particle number, surface area, or what? Environ Health Perspect. 2007;115(2):187-194. doi:10.1289/ehp.9254

32. Brockman H. Lipid monolayers: why use half a membrane to characterize protein-membrane interactions? Curr Opin Struct Biol. 1999;9(4):438-443. doi:10.1016/S0959-440X(99)80061-X

33. Franz J, Lelle M, Peneva K, Bonn M, Weidner T. SAP (E)-A cellpenetrating polyproline helix at lipid interfaces. Biochim Et Biophys Acta (BBA) Biomembr. 2016;1858(9):2028-2034. doi:10.1016/j.bbamem.2016.05.021

34. Franz J, van Zadel M-J, Weidner T. A trough for improved SFG spectroscopy of lipid monolayers. Rev Sci Instrum. 2017;88 (5):053106. doi:10.1063/1.4982050

35. Golbek TW, Franz J, Elliott Fowler J, Schilke KF, Weidner T, Baio JE. Identifying the selectivity of antimicrobial peptides to cell membranes by sum frequency generation spectroscopy. Biointerphases. 2017;12(2):02D406. doi:10.1116/1.4982710

36. Liljeblad JF, Bulone V, Rutland MW, Johnson CM. Supported phospholipid monolayers. The molecular structure investigated by vibrational sum frequency spectroscopy. $J$ Phys Chem $C$. 2011;115(21):10617-10629. doi:10.1021/jp111587e

37. Liljeblad JF, Bulone V, Tyrode E, Rutland MW, Johnson CM. Phospholipid monolayers probed by vibrational sum frequency spectroscopy: instability of unsaturated phospholipids. Biophys $J$. 2010;98(10):L50-L52. doi:10.1016/j.bpj.2010.02.009

38. Ma G, Allen HC. DPPC Langmuir monolayer at the air- water interface: probing the tail and head groups by vibrational sum frequency generation spectroscopy. Langmuir. 2006;22 (12):5341-5349. doi:10.1021/la0535227

39. Maget-Dana R. The monolayer technique: a potent tool for studying the interfacial properties of antimicrobial and membrane-lytic peptides and their interactions with lipid membranes. Biochim Et Biophys Acta (BBA) Biomembr. 1999;1462(1-2):109-140. doi:10.1016/S0005-2736(99)00203-5

40. Mauri S, Pandey R, Rzeznicka I, Lu H, Bonn M, Weidner T. Bovine and human insulin adsorption at lipid monolayers: a comparison. Front Physics. 2015;3:51. doi:10.3389/fphy. 2015.00051

41. Watry MR, Tarbuck TL, Richmond GL. Vibrational sum-frequency studies of a series of phospholipid monolayers and the associated water structure at the vapor/water interface. J Phys Chem B. 2003;107(2):512-518. doi:10.1021/jp0216878

42. Ahn D, Dhinojwala A. Sum frequency generation vibrational spectroscopy of silicone surfaces \& interfaces. In: Silicone Surface Science. Springer; 2012:23-58.

43. Shen Y-R. The principles of nonlinear optics. $N Y$ Wiley Intersci. 1984;575(p): 1984.

44. Wang H-F, Velarde L, Gan W, Fu L. Quantitative sum-frequency generation vibrational spectroscopy of molecular surfaces and interfaces: lineshape, polarization, and orientation. Anпu Rev Phys Chem. 2015;66(1):189-216. doi:10.1146/annurev-physchem $-040214-121322$ 
45. Wang H-F, Gan W, Lu R, Rao Y, Wu B-H. Quantitative spectral and orientational analysis in surface sum frequency generation vibrational spectroscopy (SFG-VS). Int Rev Phys Chem. 2005;24 (2):191-256. doi:10.1080/01442350500225894

46. Zhuang X, Miranda P, Kim D, Shen Y. Mapping molecular orientation and conformation at interfaces by surface nonlinear optics. Phys Rev B. 1999;59(19):12632. doi:10.1103/ PhysRevB.59.12632

47. Ding B, Chen Z. Molecular interactions between cell penetrating peptide Pep-1 and model cell membranes. J Phys Chem B. 2012;116(8):2545-2552. doi:10.1021/jp209604m

48. Liu Y, Jasensky J, Chen Z. Molecular interactions of proteins and peptides at interfaces studied by sum frequency generation vibrational spectroscopy. Langmuir. 2011;28(4):2113-2121. doi:10.1021/la203823t

49. Rzeznicka I, Pandey R, Schleeger M, Bonn M, Weidner T. Formation of lysozyme oligomers at model cell membranes monitored with sum frequency generation spectroscopy. Langmuir. 2014;30(26):7736-7744. doi:10.1021/la5010227

50. Schach DK, Rock W, Franz J, Bonn M, Parekh SH, Weidner T. Reversible activation of a cell-penetrating peptide in a membrane environment. J Am Chem Soc. 2015;137(38):12199-12202. doi: $10.1021 /$ jacs.5b06720

51. Thennarasu S, Huang R, Lee D-K, et al. Limiting an antimicrobial peptide to the lipid- water interface enhances its bacterial membrane selectivity: a case study of MSI-367. Biochemistry. 2010;49 (50):10595-10605. doi:10.1021/bi101394r

52. Wang J, Buck SM, Chen Z. Sum frequency generation vibrational spectroscopy studies on protein adsorption. J Phys Chem B. 2002;106(44):11666-11672. doi:10.1021/jp021363j

53. Ye S, Nguyen KT, Le Clair SV, Chen Z. In situ molecular level studies on membrane related peptides and proteins in real time using sum frequency generation vibrational spectroscopy. J Struct Biol. 2009;168(1):61-77. doi:10.1016/j.jsb.2009.03.006

54. Hu P, Qian W, Liu B, Pichan C, Chen Z. Molecular interactions between gold nanoparticles and model cell membranes: a study of nanoparticle surface charge effect. J Phys Chem C. 2016;120 (39):22718-22729. doi:10.1021/acs.jpcc.6b07565

55. Toledo-Fuentes X, Lis D, Cecchet F. Structural changes to lipid bilayers and their surrounding water upon interaction with functionalized gold nanoparticles. J Phys Chem C. 2016;120 (38):21399-21409. doi:10.1021/acs.jpcc.6b05460

56. Harper B, Thomas D, Chikkagoudar S, et al. Comparative hazard analysis and toxicological modeling of diverse nanomaterials using the embryonic zebrafish (EZ) metric of toxicity. J Nanopart Res. 2015;17(6):250. doi:10.1007/s11051-015-3051-0

57. Harper S, Usenko C, Hutchison J, Maddux B, Tanguay R. In vivo biodistribution and toxicity depends on nanomaterial composition, size, surface functionalisation and route of exposure. $J$ Exp Nanosci. 2008;3(3):195-206. doi:10.1080/17458080802378953

58. Harper SL, Carriere JL, Miller JM, Hutchison JE, Maddux BLS, Tanguay RL. Systematic evaluation of nanomaterial toxicity: utility of standardized materials and rapid assays. ACS Nano. 2011;5(6):4688-4697. doi:10.1021/nn200546k

59. Harper SL, Dahl JA, Maddux BL, Tanguay RL, Hutchison JE. Proactively designing nanomaterials to enhance performance and minimise hazard. Int $J$ Nanotechnol. 2008;5(1):124-142. doi:10.1504/IJNT.2008.016552

60. Lin S, Zhao Y, Ji Z, et al. Zebrafish high throughput screening to study the impact of dissolvable metal oxide nanoparticles on the hatching enzyme, ZHE1. Small. 2013;9(9-10):1776-1785. doi:10.1002/smll.201202128

61. Lin S, Zhao Y, Nel AE, Lin S. Zebrafish: an in vivo model for nano EHS studies. Small. 2013;9(9-10):1608-1618. doi:10.1002/ smll.201202115
62. Hill AJ, Teraoka H, Heideman W, Peterson RE. Zebrafish as a Model vertebrate for investigating chemical toxicity. Toxicol Sci. 2005;86(1):6-19. doi:10.1093/toxsci/kfi110

63. Howe $\mathrm{K}$, Clark MD, Torroja CF, et al. The zebrafish reference genome sequence and its relationship to the human genome. Nature. 2013;496(7446):498-503. doi:10.1038/nature12111

64. Tropepe V, Sive HL. Can zebrafish be used as a model to study the neurodevelopmental causes of autism? Genes Brain Behav. 2003;2(5):268-281. doi:10.1034/j.1601-183X.2003.00038.x

65. Zon LI, Peterson RT. In vivo drug discovery in the zebrafish. Nat Rev Drug Discov. 2005;4(1):35-44. doi:10.1038/nrd1606

66. Holman J, Davies PB, Nishida T, Ye S, Neivandt DJ. Sum Frequency Generation from Langmuir- Blodgett Multilayer Films on Metal and Dielectric Substrates. ACS Publications; 2005.

67. Weidner T, Apte JS, Gamble LJ, Castner DG. Probing the orientation and conformation of $\alpha$-helix and $\beta$-strand model peptides on self-assembled monolayers using sum frequency generation and NEXAFS spectroscopy. Langmuir. 2009;26(5):3433-3440. doi:10.1021/la903267x

68. Ingólfsson HI, Melo MN, Van Eerden FJ, et al. Lipid organization of the plasma membrane. $J$ Am Chem Soc. 2014;136 (41):14554-14559. doi:10.1021/ja507832e

69. Roke S, Schins J, Müller M, Bonn M. Vibrational spectroscopic investigation of the phase diagram of a biomimetic lipid monolayer. Phys Rev Lett. 2003;90(12):128101. doi:10.1103/ PhysRevLett.90.128101

70. Westerfield M, The zebrafish book: a guide for the laboratory use of zebrafish. http://zfin.org/zfinfo/zfbook/zfbk.html. Accessed May 27, 2020. 2000.

71. Kimmel CB, Ballard WW, Kimmel SR, Ullmann B, Schilling TF. Stages of embryonic development of the zebrafish. Dev Dyn. 1995;203(3):253-310. doi:10.1002/aja.1002030302

72. Usenko CY, Harper SL, Tanguay RL. Fullerene C60 exposure elicits an oxidative stress response in embryonic zebrafish. Toxicol Appl Pharmacol. 2008;229(1):44-55. doi:10.1016/j. taap.2007.12.030

73. Henn K, Braunbeck T. Dechorionation as a tool to improve the fish embryo toxicity test (FET) with the zebrafish (Danio rerio). Comp Biochem Physiol Part C. 2011;153(1):91-98.

74. Kim K-T, Tanguay RL. The role of chorion on toxicity of silver nanoparticles in the embryonic zebrafish assay. Environ Health Toxicol. 2014;29:e2014021. doi:10.5620/eht.e2014021

75. Mackiewicz MR, Hodges HL, Reed SM. C-reactive protein induced rearrangement of phosphatidylcholine on nanoparticle mimics of lipoprotein particles. J Phys Chem B. 2010;114 (16):5556-5562. doi:10.1021/jp911617q

76. Sitaula S, Mackiewicz MR, Reed SM, Gold nanoparticles become stable to cyanide etch when coated with hybrid lipid bilayers. Chem Commun. 2008;26:3013-3015. doi:10.1039/b801525b

77. Yang JA, Murphy CJ. Evidence for patchy lipid layers on gold nanoparticle surfaces. Langmuir. 2012;28(12):5404-5416. doi:10.1021/la300325p

78. Templeton AC, Hostetler MJ, Kraft CT, Murray RW. Reactivity of monolayer-protected gold cluster molecules: steric effects. J Am Chem Soc. 1998;120(8):1906-1911.

79. Kreibig U, Genzel L. Optical absorption of small metallic particles. Surf Sci. 1985;156:678-700. doi:10.1016/0039-6028(85)90239-0

80. Storhoff JJ, Lazarides AA, Mucic RC, Mirkin CA, Letsinger RL, Schatz GC. What controls the optical properties of DNA-linked gold nanoparticle assemblies? J Am Chem Soc. 2000;122 (19):4640-4650. doi:10.1021/ja9938251

81. Engstrom AM, Wu H, Mackiewicz MR, Harper SL. Hybrid lipid-coated silver nanoparticles with long-chain hydrophobic thiol surface coatings show decreased toxicity compared to those without robust surface coatings. Int J Eng Res Appl. 2020;10:15677-15693. 
82. Manshian BB, Pokhrel S, Mädler L, Soenen SJ. The impact of nanoparticle-driven lysosomal alkalinization on cellular functionality. J Nanobiotechnology. 2018;16(1):85. doi:10.1186/ s12951-018-0413-7

83. Schutz I, Lopez-Hernandez T, Gao Q, et al. Lysosomal dysfunction caused by cellular accumulation of silica nanoparticles. J Biol Chem. 2016;291(27):14170-14184. doi:10.1074/jbc.M115.710947

84. Martinez Legaspi S, Segatori L. Aggregation behavior of nanoparticle-peptide systems affects autophagy. Bioconjug Chem. 2019;30(7):1986-1997. doi:10.1021/acs.bioconjchem.9b00266

85. Rathore B, Sunwoo K, Jangili P, et al. Nanomaterial designing strategies related to cell lysosome and their biomedical applications: A review. Biomaterials. 2019;211:25-47. doi:10.1016/j. biomaterials.2019.05.002

86. Sovago M, Wurpel GW, Smits M, Müller M, Bonn M. Calciuminduced phospholipid ordering depends on surface pressure. $J \mathrm{Am}$ Chem Soc. 2007;129(36):11079-11084. doi:10.1021/ja071189i

87. Hu P, Zhang X, Zhang C, Chen Z. Molecular interactions between gold nanoparticles and model cell membranes. Phys Chem Chem Phys. 2015;17(15):9873-9884. doi:10.1039/C5CP00477B

88. Liu J, Conboy JC. 1, 2-diacyl-phosphatidylcholine flip-flop measured directly by sum-frequency vibrational spectroscopy. Biophys J. 2005;89(4):2522-2532. doi:10.1529/biophysj.105.065672

89. Yi X, Shi X, Gao H. Cellular uptake of elastic nanoparticles. Phys Rev Lett. 2011;107(9):098101. doi:10.1103/PhysRevLett.107.098101

90. Bahrami AH, Raatz M, Agudo-Canalejo J, et al. Wrapping of nanoparticles by membranes. Adv Colloid Interface Sci. 2014;208:214-224. doi:10.1016/j.cis.2014.02.012

91. Hu P, Zhang X, Li Y, Pichan C, Chen Z. Molecular interactions between silver nanoparticles and model cell membranes. Top Catal. 2018;61(9-11):1148-1162. doi:10.1007/s11244-018-0926-1

92. Harper KL, Allen HC. Competition between DPPC and SDS at the Air- Aqueous Interface. Langmuir. 2007;23(17):8925-8931. doi:10.1021/la7006974
93. Tyrode E, Hedberg J. A comparative study of the $\mathrm{CD}$ and $\mathrm{CH}$ stretching spectral regions of typical surfactants systems using VSFS: orientation analysis of the terminal $\mathrm{CH} 3$ and $\mathrm{CD} 3$ groups. J Phys Chem C. 2011;116(1):1080-1091. doi:10.1021/jp210013g

94. Van Lehn RC, Atukorale PU, Carney RP, et al. Effect of particle diameter and surface composition on the spontaneous fusion of monolayer-protected gold nanoparticles with lipid bilayers. Nano Lett. 2013;13(9):4060-4067. doi:10.1021/n1401365n

95. Baio J, Weidner T, Brison J, Graham D, Gamble LJ, Castner DG. Amine terminated SAMs: investigating why oxygen is present in these films. J Electron Spectros Relat Phenomena. 2009;172(1-3):2-8. doi:10.1016/j.elspec.2009.02.008

96. Fowler JE, Kleinteich T, Franz J, et al. Surface chemistry of the frog sticky-tongue mechanism. Biointerphases. 2018;13 (6):06E408. doi:10.1116/1.5052651

97. Dominguez H, Smondyrev A, Berkowitz M. Computer simulations of phosphatidylcholine monolayers at air/water and CCl4/ water interfaces. J Phys Chem B. 1999;103(44):9582-9588. doi:10.1021/jp991352z

98. Mohwald H. Phospholipid and phospholipid-protein monolayers at the air/water interface. Annu Rev Phys Chem. 1990;41 (1):441-476. doi:10.1146/annurev.pc.41.100190.002301

99. Li Y, Gu N. Thermodynamics of charged nanoparticle adsorption on charge-neutral membranes: a simulation study. J Phys Chem B. 2010;114(8):2749-2754. doi:10.1021/jp904550b

100. Reif DM, Truong L, Mandrell D, Marvel S, Zhang G, Tanguay RL. High-throughput characterization of chemical-associated embryonic behavioral changes predicts teratogenic outcomes. Arch Toxicol. 2016;90(6):1459-1470. doi:10.1007/s00204-015-1554-1

101. Roiter Y, Ornatska M, Rammohan AR, Balakrishnan J, Heine DR, Minko S. Interaction of nanoparticles with lipid membrane. Nano Lett. 2008;8(3):941-944. doi:10.1021/n10800801
International Journal of Nanomedicine

\section{Publish your work in this journal}

The International Journal of Nanomedicine is an international, peerreviewed journal focusing on the application of nanotechnology in diagnostics, therapeutics, and drug delivery systems throughout the biomedical field. This journal is indexed on PubMed Central, MedLine, CAS, SciSearch ${ }^{\mathbb{}}$, Current Contents ${ }^{\mathbb{R}} /$ Clinical Medicine,

\section{Dovepress}

Journal Citation Reports/Science Edition, EMBase, Scopus and the Elsevier Bibliographic databases. The manuscript management system is completely online and includes a very quick and fair peer-review system, which is all easy to use. Visit http://www.dovepress.com/ testimonials.php to read real quotes from published authors. 